\title{
Overexpression of excision repair cross-complementing 1 gene associates with higher risk of therapeutic failure after definitive chemoradiation for unresectable non-small cell lung cancer
}

\author{
Matthew P. Deek ${ }^{1}$, Nikhil Yegya-Raman ${ }^{2}$, Parima Daroui ${ }^{3}$, Sairam Balasubramanian ${ }^{4}$, Jyoti Malhotra ${ }^{5}$, \\ Dirk Moore $^{6}$, Malini Patel ${ }^{5}$, Shang-Jui Wang ${ }^{7}$, Joseph Aisner ${ }^{5}$, Salma K. Jabbour ${ }^{7}$ \\ ${ }^{1}$ Department of Radiation Oncology and Molecular Radiation Sciences, Johns Hopkins University School of Medicine, Baltimore, MD, USA; \\ ${ }^{2}$ Department of Radiation Oncology, University of Pennsylvania, Philadelphia, PA, USA; ${ }^{3}$ Department of Radiation Oncology, The Permanente \\ Medical Group, Santa Clara Cancer Treatment Center, Santa Clara, CA, USA; ${ }^{4}$ Department of Emergency Medicine, Sinai Hospital Baltimore, \\ Baltimore, MD, USA; ${ }^{5}$ Department of Medical Oncology, Robert Wood Johnson Medical School, Rutgers University, NJ, USA; ${ }^{6}$ Department of

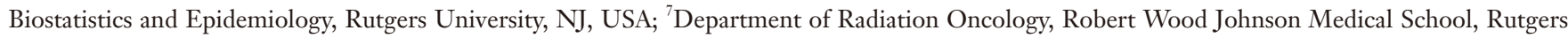 \\ University, NJ, USA \\ Contributions: (I) Conception and design: MP Deek, J Aisner, SK Jabbour; (II) Administrative support: MP Deek, SK Jabbour; (III) Provision of study \\ materials or patients: MP Deek, SK Jabbour; (IV) Collection and assembly of data: MP Deek, SK Jabbour; (V) Data analysis and interpretation: MP \\ Deek, SK Jabbour; (VI) Manuscript writing: All authors; (VII) Final approval of manuscript: All authors. \\ Correspondence to: Salma K. Jabbour, MD. Professor, Vice Chair of Clinical Research \& Faculty Development, Department of Radiation Oncology, \\ Rutgers Cancer Institute of New Jersey, Robert Wood Johnson Medical School, Rutgers University, 195 Little Albany St., New Brunswick, NJ \\ 08901, USA. Email: jabbousk@cinj.rutgers.edu.
}

Background: Locally advanced non-small cell lung cancer (NSCLC) is typically treated with concurrent chemoradiation (CRT). Excision Repair Cross-Complementing 1 (ERCC1) is a protein involved in DNA damage repair. The objective of this study was to assess whether higher tumoral ERCC1 expression would associate with worse clinical outcomes in NSCLC treated with CRT.

Methods: Twenty-five patients were included. Relative expression levels of messenger RNA (mRNA) for ERCC1 were measured with a quantitative reverse transcription polymerase chain reaction (qRT-PCR) and expressed as scaled ERCC1 mRNA gene expression value. Patients were followed every 3 months with history, physical exam, and imaging to assess clinical outcomes. We evaluated the associations between ERCC1, as well as other prognostic variables including stage, age, gender, race, histology, RT dose, performance status, and progression free survival (PFS) and overall survival (OS) with Kaplan-Meier method and Cox regression.

Results: Recursive partitioning analysis identified a GeneExp cutoff of 1.54. Higher ERCC1 expression was associated with worse PFS [hazard ratio $(\mathrm{HR})=1.70, \mathrm{P}=0.04$ ] and trended towards worse $\mathrm{OS}(\mathrm{HR}=1.53$, $\mathrm{P}=0.11)$. Increasing tumor volume $(\mathrm{HR}=1.001, \mathrm{P}=0.055)$, squamous cell $(\mathrm{HR}=7.86, \mathrm{P}=0.008)$ and poorly differentiated histology $(\mathrm{HR}=5.25, \mathrm{P}=0.06)$ also associated with worse $\mathrm{OS}$. The cumulative incidence of local recurrence at 1 year trended higher with ERCC1 GeneExp $\geq 1.54$ (78.1\%) compared to ERCC1 GeneExp $<1.54(14.9 \%, \mathrm{P}=0.08)$. Distant relapse at 1 year was $72 \%$ with tumor ERCC1 expression $\geq 1.54$ and $52 \%$ with ERCC1 expression $<1.54(\mathrm{P}=0.28)$.

Conclusions: Higher ERCC1 expression by qRT-PCR appears to correlate with worse PFS in locally advanced NSCLC treated with CRT. However, the overall sample size of the population was small; thus, larger studies are warranted to integrate molecular biomarkers to identify patients who might benefit from treatment intensification.

Keywords: Excision repair cross-complementing 1 (ERCC1); lung cancer; chemoradiation 
Submitted Jan 22, 2021. Accepted for publication May 18, 2021.

doi: 10.21037/apm-21-182

View this article at: https://dx.doi.org/10.21037/apm-21-182

\section{Introduction}

Locally advanced non-small cell lung cancer (NSCLC) remains a leading cause of cancer-related mortality in the United States (1). Concurrent chemoradiation therapy (CRT) is a cornerstone in the treatment for these patients and results in improved overall survival (OS) when compared to sequential CRT or either treatment alone (2-4). However, the long-term outcomes for patients with locally advanced disease, regardless of treatment paradigm, remain poor with 5 -year OS rates following CRT of $30 \%$ (5). The integration of consolidative programmed death ligand-1 (PDL-1) blockade after CRT results in improved OS rates for those without progressive disease or toxicity after CRT, however, median progression free survival (PFS) of 17.2 months and 2 -year OS of $66.3 \%$ still warrant further improvements in therapy (6). Therefore, better treatments are needed along with improved predictors of treatment response to optimize the stratification of those patients who might benefit from treatment intensification.

Radiotherapy and chemotherapy are DNA damaging agents that lead to cell death, however therapeutic resistance emerges when malignant cells can repair this DNA injury following therapy. The protein Excision Repair CrossComplementing 1 (ERCC1) is one of a complex of proteins involved in DNA repair through multiple mechanisms including the nucleotide excision repair pathway where it forms a heterodimer with xeroderma pigmentosum complementation group $\mathrm{F}$ forming a nuclease. This protein complex cleaves DNA in helix distorting lesions allowing for repair of damage and thus is important in repair of injury from platinum chemotherapy agents that cause DNA intra-strand crosslinks ultimately leading to cell death. Thus, ERCC1 is important in the development of resistance to platinum agents (7). Additionally, the ERCC1-xeroderma pigmentosum complementation group $\mathrm{F}$ complex is also involved in DNA double strand break repair that can also promote resistance to radiotherapy (8).

Higher expression levels of ERCC1 have been correlated with worse outcomes in multiple malignancies including breast, head and neck, esophageal, gastric, colorectal, ovarian, and lung cancers (9-16). However, in NSCLC, the majority of work investigating ERCC1 has been to elucidate its impact in individuals who received treatment with chemotherapy. For example, in those with completely resected NSCLC, expression of ERCC1 negated any benefit of adjuvant cisplatin, while those who did not express the protein had significantly improved 5-year OS (47\% vs. 39\%), a result replicated in other classes of chemotherapeutic agents (17). However, little work has been done to investigate its impact within the realm of individuals undergoing definitive CRT for locally advanced, inoperable NSCLC. Given efforts at treatment escalation in NSCLC have failed to show a clear benefit, biomarkers such as ERCC1 might provide information to allow better personalization and success in these efforts. Additionally, the potentially poorer outcomes seen in cancers with ERCC1 mutations might offer a new therapeutic avenue to target in order to improve outcomes. Given that about 20$30 \%$ of NSCLC cases present with locally advanced disease, for which CRT is standard of care, we aimed to investigate the role of ERCC1 expression in therapeutic resistance within this cohort. We hypothesized higher levels of ERCC1 expression would correlate with inferior oncologic outcomes in individuals with locally advanced NSCLC treated with definitive CRT. We present the following article in accordance with the REMARK reporting checklist (available at http://dx.doi.org/10.21037/apm-21-182).

\section{Methods}

\section{Patient population}

After Rutgers University Institutional Review Board (IRB)approval protocol (CINJ 031205), we retrospectively reviewed patients for inclusion criteria which where locally advanced (stage III) NSCLC treatment with definitive concurrent CRT with available tissue for processing. In total, 25 patients were included in the study. Before CRT, work-up included a complete history and physical examination, complete blood count, serum chemistry profile, chest computed tomography (CT) scan, positron emission tomography (PET) scan, brain magnetic resonance imaging and mass or nodal biopsy. Clinical staging was defined using the American Joint Committee on Cancer $7^{\text {th }}$ edition criteria. This study was conducted in accordance 
with the Declaration of Helsinki (as revised in 2013) and individual consent for this retrospective analysis was waived.

During treatment, patients were placed in a supine position with arms up to allow accurate reproducibility of the target lesion with each treatment session. A large rigid pillow or mold was created for each patient. Radiation therapy (RT) was delivered using 3D conformal (3D-CRT) or intensity-modulated technique (IMRT). RT was delivered through anteroposterior fields first to 40 Gray (Gy) (18) in 1.8 or 2 Gy per fraction per day followed by oblique fields to avoid the spinal cord for an additional 20-26 Gy for a total RT dose of typically 60-66 Gy. For involved bilateral mediastinal lymph nodes, IMRT was employed either from the onset of RT or for the boost/offcord component of RT.

The typical chemotherapy regimen consisted of intravenous infusional drug delivery of weekly paclitaxel $\left(45 \mathrm{mg} / \mathrm{m}^{2}\right)$ plus carboplatin [area under the curve (AUC) $=2]$ or every 3 -week etoposide $\left(50 \mathrm{mg} / \mathrm{m}^{2}\right)$ plus cisplatin $\left(50 \mathrm{mg} / \mathrm{m}^{2}\right)$. Following treatment, patients were followed every 3 months for years $1-2$, every 4 months for years $3-4$, and every 6 months for year 5 with history, physical exam, and anatomic imaging to assess disease status.

\section{Sample processing}

Messenger RNA (mRNA) was isolated from paraffinembedded pretreatment tumor samples and relative expression levels of $E R C C 1 / B$-actin were measured with a quantitative reverse transcription polymerase chain reaction (qRT-PCR) process by Response Genetics. qRT-PCR was chosen based on limitations with immunohistochemistry using ERCC1 (19). Actin was used as a control due to constant degradation rate of mRNA. An ERCC1 GeneExp value, a scaled ERCC1 mRNA expression value, was calculated based on three known reference samples run on each PCR plate. A constitutively expressed control gene (Actin) was to correct for the RNA variable loading values.

\section{Statistical analysis}

Baseline characteristics were calculated for the population as a whole. The normality of continuous variables was checked using a Kolmogorov-Smirnov test. ERCC1 expression was then dichotomized based on a recursive partitioning analysis (cut point of 1.54) and differences in baseline characteristics were compared between these two groups using a chi squared or Fisher exact test for categorical variables or $t$-test or a Mann Whitney $\mathrm{U}$ test for continuous variables. Univariable Cox proportional hazard ratios (HRs) were used to identify variables with a priori belief to be associated with PFS (ERCC1, stage, age, gender, race, histology, RT dose, performance status) where events were local, regional, distant recurrence, or death, and OS. Kaplan-Meier curves were generated for PFS and OS and differences evaluated using the log rank test. Competing risk and Fine-Gray analysis was performed to calculate risk of locoregional and distant recurrence with death, local recurrence (for distant recurrence) or distant recurrence (for local recurrence) as competing events. All analyses were conducted using R: a language and environment for statistical computing.

\section{Results}

In total, 25 patients' tumor biopsies were available for analysis. Median follow up time was 8.6 (range, 0.23110.1) months. Median age of the group was 69.8 (range, 54.8-82.6) years. Patients were split evenly between male $(52 \%)$ and female $(48 \%)$. The majority were Caucasian (88\%) and all had stage III disease (28\% stage IIIA, $72 \%$ stage IIIB). Median RT dose was 60 (range, 50-72) Gy and median tumor ERCC1 GeneExp value for the group was 1.28 (range, 0.34-4.39). There were no significant differences in distribution of baseline characteristics between patients with tumor ERCC1 GeneExp values $\geq 1.54$ vs. $<1.54$ (Table 1).

On univariable analysis, higher tumor ERCC1 expression was associated with worse PFS $[\mathrm{HR}=1.70,95 \%$ confidence interval (CI): (1.01-2.87), $\mathrm{P}=0.04$ ] (Table 2). Squamous cell carcinoma (SCC) histology was also associated with worse PFS on univariable analysis [HR $=3.6,95 \%$ CI: $(0.96-13.5)$, $\mathrm{P}=0.06]$. Patients with ERCC1 GeneExp $\geq 1.54$ had median PFS of 4.1 months compared to 6.2 months in patients with ERCC1 GeneExp $<1.54(\mathrm{P}=0.22$, Figure 1).

Higher tumor ERCC1 expression also trended towards worse OS [HR $=1.53,95 \% \mathrm{CI}$ : $(0.91-2.55), \mathrm{P}=0.11]$. On univariable analysis increasing tumor volume $[\mathrm{HR}=1.001$, 95\% CI: (0.999-1.002), $\mathrm{P}=0.06]$ as well as SCC $[\mathrm{HR}=7.86$, 95\% CI: (1.70-36.3), $\mathrm{P}=0.008]$ and poorly differentiated histology [HR $=5.25,95 \% \mathrm{CI}$ : $(0.93-29.7), \mathrm{P}=0.06]$ were also associated with increased risk of death. However, tumors with ERCC1 GeneExp cutoff $\geq 1.54$ did not show differences in OS when compared to individuals with tumor ERCC1 GeneExp values <1.54 (8.7 vs. 8.6 months, $\mathrm{P}=0.35$ ) (Figure 2).

Patients with local recurrence had higher median levels of ERCC1 GeneExp (1.83 vs. 0.87, $\mathrm{P}=0.16$ ) (Figure 3). The 
Table 1 Baseline characteristics

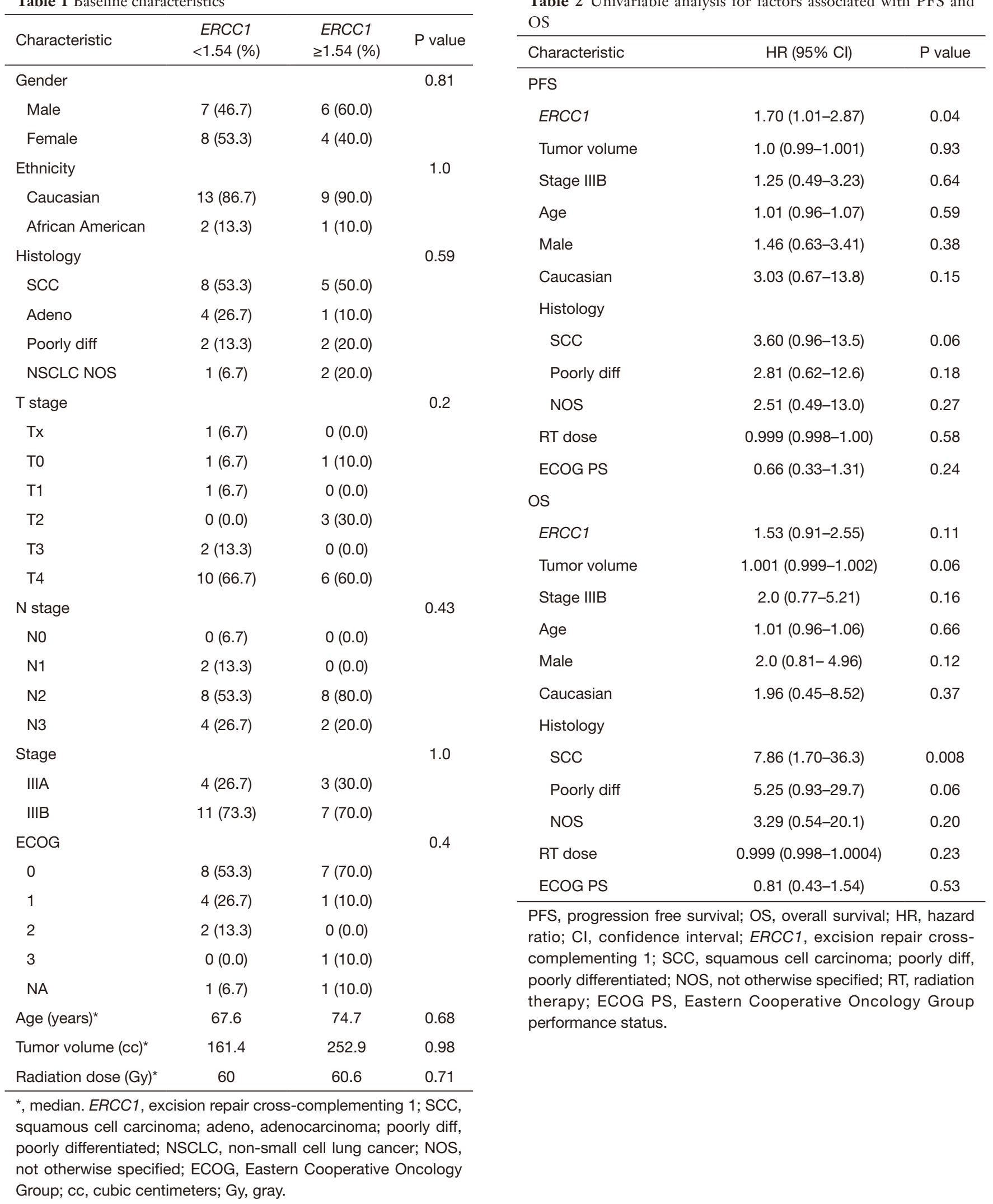

Table 2 Univariable analysis for factors associated with PFS and

PFS, progression free survival; OS, overall survival; HR, hazard poorly differentiated; $N O S$, therapy; ECOG PS, Eastern Cooperative Oncology Group performance status. 


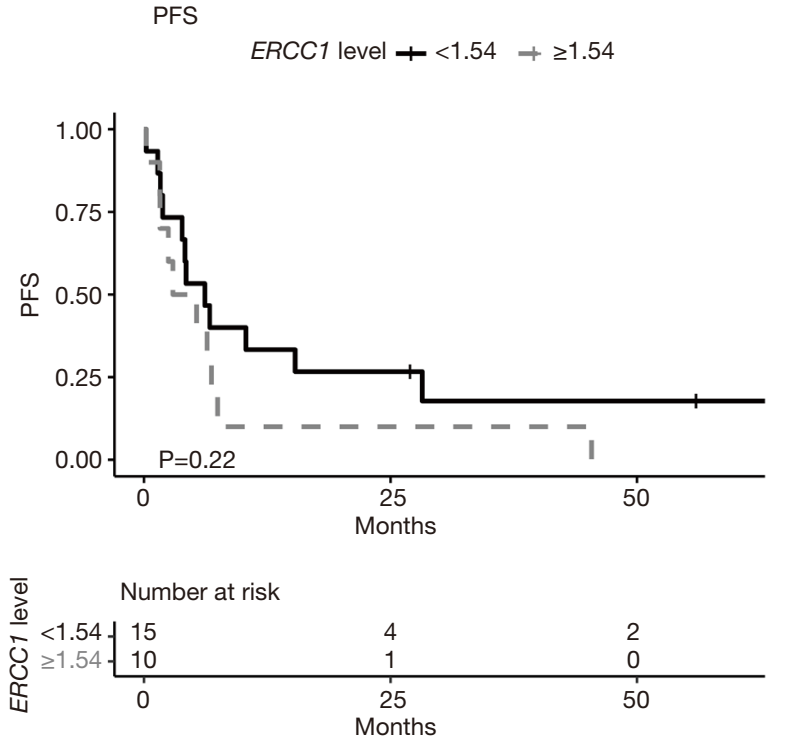

Figure 1 PFS stratified by ERCC1 expression. PFS, progression free survival; ERCC1, excision repair cross-complementing 1.

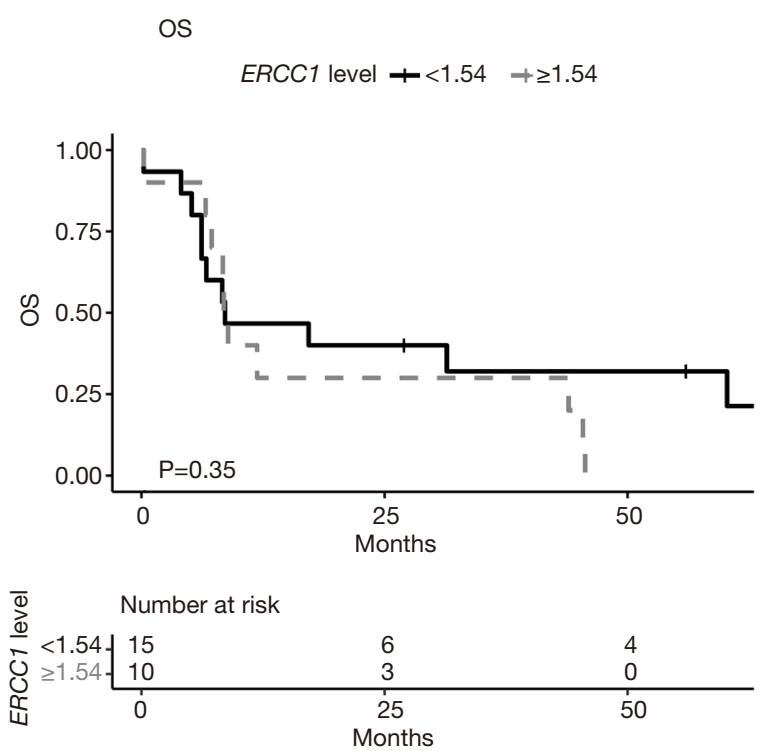

Figure 2 OS stratified by ERCC1 expression. OS, overall survival; ERCC1, excision repair cross-complementing 1.

cumulative incidence of local failure at 1 year was higher with ERCC1 GeneExp $\geq 1.54$ (78.1\%) compared to ERCC1 GeneExp <1.54 (14.9\%, P=0.08) (Figure 4). On univariable competing risk analysis, ERCC1 GeneExp value $\geq 1.54$ (HR $=2.18$ ) was associated with higher risk of local recurrence $(\mathrm{P}=0.29)$. Cumulative incidence of distant relapse at 1 year

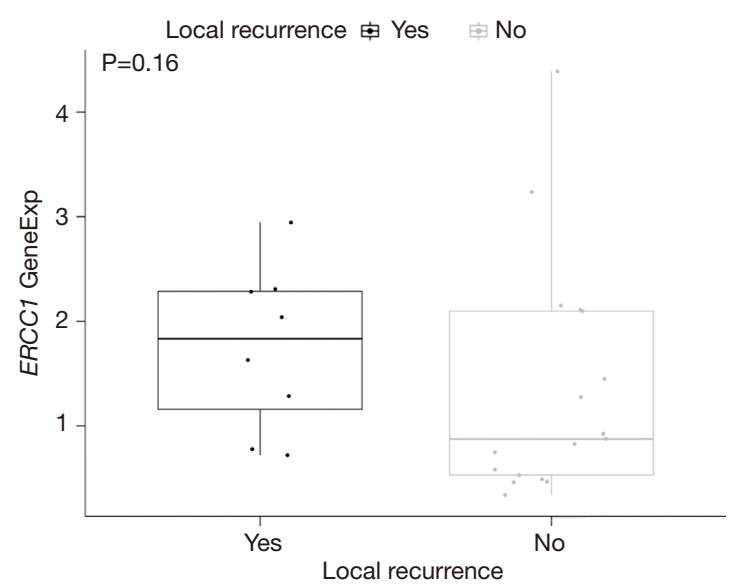

Figure 3 Median ERCC1 expression levels stratified by local failure. ERCC1, excision repair cross-complementing 1.

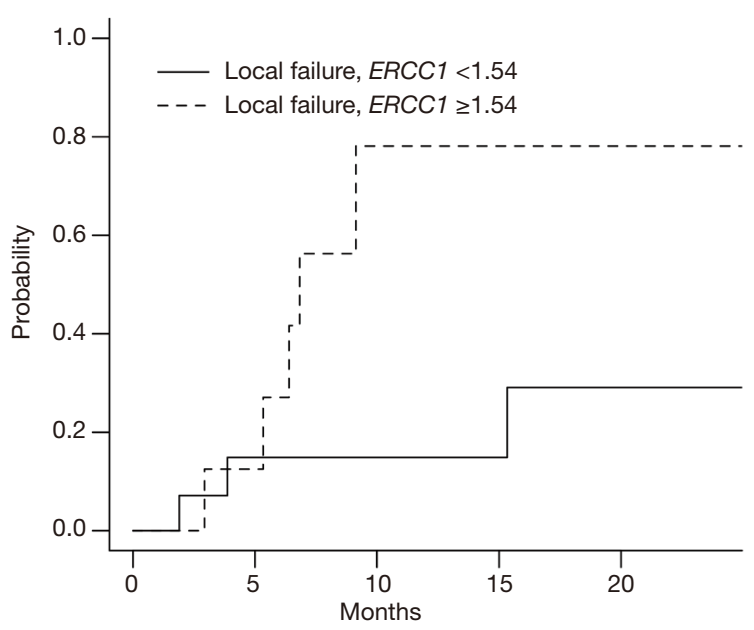

Figure 4 Local failure following chemoradiation stratified by ERCC1 expression. ERCC1, excision repair cross-complementing 1.

was $72 \%$ for individuals with tumor ERCC1 expression $\geq 1.54$ and $52 \%$ in individuals with tumor ERCC1 expression $<1.54(\mathrm{P}=0.28)$.

\section{Discussion}

This is the first report, to our knowledge, investigating the role of ERCC1 expression in oncologic outcomes for individuals with locally advanced NSCLC treated with definitive CRT. Our results suggest that higher expression of ERCC1, a protein involved in the DNA repair process, is associated with worse PFS and a trend to worse OS in this cohort of patients, conferring resistance to RT with 
concurrent platinum doublet chemotherapy.

ERCC1 plays an important role in treatment response and higher levels of expression is a well-established predictor for poor oncologic outcomes in a multitude of malignancies including breast, head and neck, esophageal, gastric, colorectal, ovarian, and lung cancer (9-16). Most work in NSCLC has specifically focused on its role in response to adjuvant chemotherapy following surgical resection where elevated expression is closely linked to worse OS (17). Here we report ERCC1 expression similarly correlated with PFS in those with locally advanced NSCLC undergoing a course of definitive CRT. As treatment paradigms shift in NSCLC continued efforts to understand the role of ERCC1 and other DNA repair proteins play in therapeutic resistance is of great importance. The PACIFIC trial demonstrated impressive benefits in PFS and OS with the use of PD-L1 blockade using durvalumab following CRT in unresectable NSCLC (6) leading to the rapid adoption of immunotherapy as an acceptable standard of care. The results of this study now lead to new questions including whether we can identify patients who would best benefit from consolidative therapy. There is some work to suggest polymorphisms in DNA repair pathways similarly influence outcomes with targeted agents. For example, polymorphisms in X-ray repair crosscomplementing group 1 (XRCC1) gene correlate with improved responses to gefitinib in never smokers with adenocarcinoma (20). Specifically, patients who had the XRCC1 arginine polymorphism at codon 399 had a higher response rate to gefitinib $(71 \%$ vs. $36 \% ; \mathrm{P}=0.002)$ than patients with the glutamine allele. Therefore, future work to better understand the role DNA repair pathway proteins plays in treatment resistance to targeted molecular agents or immunotherapy, especially in combination with RT, a regimen likely to continue to increase in usage in the near future, is unquestionably needed.

ERCC1 expression appears to be an important prognostic biomarker that is able to predict a patient's clinical course following CRT in NSCLC. As a better understanding of the molecular framework of cancer has emerged so, too, have prognostic biomarkers in other sites such as DPC4/ SMAD4 expression in pancreatic cancer $(21,22)$ or HPV status in head and neck cancer (23). Additionally, beyond biological markers there has also been identification of radiologic markers, such as change in tumor volume on cone beam CT during CRT in NSCLC (24) or PET/CT response following induction chemotherapy for esophageal cancers (CALGB 80803) that can inform outcomes. While prognostic markers provide important information to clinicians and patients, predictive markers might be able to go one step further to help clinicians choose one therapeutic avenue over another. For example, gene profiling in muscle invasive bladder cancer has identified differential signatures of T-cell activation and interferon gamma signaling that associated with improved disease specific survival when treated with CRT compared to surgical resection (25). Additionally, patients with an adenineadenine polymorphism at codon 8092 have improved PFS (7.5 vs. 6.4 months; $\mathrm{P}=0.024$ ) with gefitinib compared to gemcitabine plus cisplatin in NSCLC (20). This has lead to efforts to "tailor" systemic therapy based on underlying genomic profiles, which has resulted in improvements in OS and PFS in NSCLC patients (26). Therefore, as additional therapeutic options become available in the treatment of NSCLC, additional studies are needed to differentiate how the molecular underpinnings of individual patient's tumors might influence response to treatment and how these differences can be exploited to improve the personalization of care.

ERCC1 expression seems to have a large impact on rate of locoregional control within our cohort. While local control rates have improved over time with advances in systemic therapy and radiation technique failure rates after 60 Gy of CRT can still be as high as 25\% (27). Given this, RTOG 0617 attempted to answer whether radiation dose escalation to 74 Gy might improve rates of local control and OS. Dose escalation did not appear to uniformly improve outcomes and, rather, was associated with worse OS (20.3 vs. 28.7 months). Factors associated with decrements in OS were esophagitis grade and heart dose suggesting worse toxicity from higher radiation dose contributed to the poor outcomes with 74 Gy. Using biomarkers such as ERCC1 in the future might help to better select which patients could maximally benefit from dose escalated therapy due to unfavorable tumor biology while attempting to balance the resultant morbidity. Additionally, biomarkers can also be developed to predict who is likely to be more sensitive to normal tissue side effects from RT to assist in tailoring radiation plans (28).

One advantage of this study was our use of qRT-PCR to define ERCC1 mRNA expression levels as compared to previous studies, which most commonly performed immunohistochemistry-based techniques using the mouse monoclonal antibody $8 \mathrm{~F} 1$ to probe at the protein level. However, it is not known which peptide sequence this antibody recognizes and calls into question its specificity, 
representing a major weakness of an immunohistochemistry technique (19). This concern is supported by the fact a validation set of 494 patients were not able to validate the predictive effect of immunostaining for ERCC1 protein (19). Furthermore, none of the 16 antibodies tested in the validation study were able to distinguish between the four different ERCC1 protein isoforms, which is important as only one isoform produces a protein with the capability for nucleotide excision repair and cisplatin resistance. Thus, future studies should take into account the technique for identifying ERCC1 expression and transcriptional analysis might therefore be preferred.

This study has several limitations. First, its small sample size precluded investigation into how clinical variables might have interacted with ERCC1 expression to influence outcomes. Larger studies are needed in the future to allow for multivariable analysis to adjust for potential confounding factors. Thus, the analysis here aims to lay groundwork for future studies. Additionally, the retrospective nature of this study means there could be inherent biases and heterogeneity of the population, which makes the results at best hypothesis generating. However, in the context of available literature our study adds to the evidence ERCC1 plays an important role in therapeutic outcomes in NSCLC. Future studies might focus on the role of ERCC1 in combination with other DNA repair proteins in therapeutic resistance as well as investigating how leveraging knowledge of ERCC1 expression might be incorporated into treatment intensification efforts to improve the poor outcomes seen with locally advanced NSCLC.

\section{Conclusions}

Higher ERCC1 expression appears to correlate with worse PFS in locally advanced NSCLC treated with CRT and rates of local failure appear to vary based on expression level, however this study was limited by sample size. Future studies are warranted to integrate molecular biomarkers to identify patients who might benefit from treatment intensification.

\section{Acknowledgments}

ERCC1 testing was completed by Response Genetics in kind thanks to Drs. Miriana Moran and Stephanie Astrow.

Funding: None.

\section{Footnote}

Reporting Checklist: The authors have completed the REMARK reporting checklist. Available at http://dx.doi. org/10.21037/apm-21-182

Data Sharing Statement: Available at http://dx.doi. org/10.21037/apm-21-182

Conflicts of Interest: All authors have completed the ICMJE uniform disclosure form (available at http://dx.doi. org/10.21037/apm-21-182). The authors have no conflicts of interest to declare.

Ethical Statement: The authors are accountable for all aspects of the work in ensuring that questions related to the accuracy or integrity of any part of the work are appropriately investigated and resolved. This study was conducted in accordance with the Declaration of Helsinki (as revised in 2013) and individual consent for this retrospective analysis was waived. The study was approved by Rutgers University Institutional Review Board (IRB) (No. CINJ 031205).

Open Access Statement: This is an Open Access article distributed in accordance with the Creative Commons Attribution-NonCommercial-NoDerivs 4.0 International License (CC BY-NC-ND 4.0), which permits the noncommercial replication and distribution of the article with the strict proviso that no changes or edits are made and the original work is properly cited (including links to both the formal publication through the relevant DOI and the license). See: https://creativecommons.org/licenses/by-nc-nd/4.0/.

\section{References}

1. Boloker G, Wang C, Zhang J. Updated statistics of lung and bronchus cancer in United States (2018). J Thorac Dis 2018;10:1158-61.

2. Curran WJ Jr, Paulus R, Langer CJ, et al. Sequential vs. concurrent chemoradiation for stage III non-small cell lung cancer: randomized phase III trial RTOG 9410. J Natl Cancer Inst 2011;103:1452-60.

3. Sause W, Kolesar P, Taylor S IV, et al. Final results of phase III trial in regionally advanced unresectable nonsmall cell lung cancer: Radiation Therapy Oncology Group, Eastern Cooperative Oncology Group, and 
Southwest Oncology Group. Chest 2000;117:358-64.

4. Furuse K, Fukuoka M, Kawahara M, et al. Phase III study of concurrent versus sequential thoracic radiotherapy in combination with mitomycin, vindesine, and cisplatin in unresectable stage III non-small-cell lung cancer. J Clin Oncol 1999; 17:2692-9.

5. Bradley JD, Hu C, Komaki RR, et al. Long-term results of NRG oncology RTOG 0617: standard- versus highdose chemoradiotherapy with or without cetuximab for unresectable stage III non-small-cell lung cancer. J Clin Oncol 2020;38:706-14.

6. Antonia SJ, Villegas A, Daniel D, et al. Overall survival with durvalumab after chemoradiotherapy in stage III NSCLC. N Engl J Med 2018;379:2342-50.

7. Gossage L, Madhusudan S. Current status of excision repair cross complementing-group 1 (ERCC1) in cancer. Cancer Treat Rev 2007;33:565-77.

8. Ahmad A, Robinson AR, Duensing A, et al. ERCC1-XPF endonuclease facilitates DNA double-strand break repair. Mol Cell Biol 2008;28:5082-92.

9. Johung K, Rewari A, Wu H, et al. Role of excision repair cross-complementation 1 expression as a prognostic marker for response to radiotherapy in early-stage laryngeal cancer. Head Neck 2013;35:852-7.

10. Goyal S, Parikh RR, Green C, et al. Clinicopathologic significance of excision repair cross-complementation 1 expression in patients treated with breast-conserving surgery and radiation therapy. Int J Radiat Oncol Biol Phys 2010;76:679-84.

11. Takenaka T, Yano T, Kiyohara C, et al. Effects of excision repair cross-complementation group 1 (ERCC1) single nucleotide polymorphisms on the prognosis of non-small cell lung cancer patients. Lung Cancer 2010;67:101-7.

12. Kwon HC, Roh MS, Oh SY, et al. Prognostic value of expression of ERCC1, thymidylate synthase, and glutathione S-transferase P1 for 5-fluorouracil/oxaliplatin chemotherapy in advanced gastric cancer. Ann Oncol 2007;18:504-9.

13. Warnecke-Eberz U, Metzger R, Miyazono F, et al. High specificity of quantitative excision repair crosscomplementing 1 messenger RNA expression for prediction of minor histopathological response to neoadjuvant radiochemotherapy in esophageal cancer. Clin Cancer Res 2004;10:3794-9.

14. Shirota Y, Stoehlmacher J, Brabender J, et al. ERCC1 and thymidylate synthase mRNA levels predict survival for colorectal cancer patients receiving combination oxaliplatin and fluorouracil chemotherapy. J Clin Oncol
2001;19:4298-304.

15. Metzger R, Leichman CG, Danenberg KD, et al. ERCC1 mRNA levels complement thymidylate synthase mRNA levels in predicting response and survival for gastric cancer patients receiving combination cisplatin and fluorouracil chemotherapy. J Clin Oncol 1998;16:309-16.

16. Dabholkar M, Bostick-Bruton F, Weber C, et al. ERCC1 and ERCC2 expression in malignant tissues from ovarian cancer patients. J Natl Cancer Inst 1992;84:1512-7.

17. Holm B, Mellemgaard A, Skov T, et al. Different impact of excision repair cross-complementation group 1 on survival in male and female patients with inoperable non-small-cell lung cancer treated with carboplatin and gemcitabine. J Clin Oncol 2009;27:4254-9.

18. Legrand P, Collins B, Blangy S, et al. The atomic structure of the phage Tuc2009 baseplate tripod suggests that host recognition involves two different carbohydrate binding modules. MBio 2016;7:e01781-15.

19. Friboulet L, Olaussen KA, Pignon JP, et al. ERCC1 isoform expression and DNA repair in non-small-cell lung cancer. N Engl J Med 2013;368:1101-10.

20. Han JY, Yoon KA, Park JH, et al. DNA repair gene polymorphisms and benefit from gefitinib in never-smokers with lung adenocarcinoma. Cancer 2011;117:3201-8.

21. Herman JM, Jabbour SK, Lin SH, et al. Smad4 loss correlates with higher rates of local and distant failure in pancreatic adenocarcinoma patients receiving adjuvant chemoradiation. Pancreas 2018;47:208-12.

22. Iacobuzio-Donahue CA, Fu B, Yachida S, et al. DPC4 gene status of the primary carcinoma correlates with patterns of failure in patients with pancreatic cancer. J Clin Oncol 2009;27:1806-13.

23. Ang KK, Harris J, Wheeler R, et al. Human papillomavirus and survival of patients with oropharyngeal cancer. N Engl J Med 2010;363:24-35.

24. Jabbour SK, Kim S, Haider SA, et al. Reduction in tumor volume by cone beam computed tomography predicts overall survival in non-small cell lung cancer treated with chemoradiation therapy. Int J Radiat Oncol Biol Phys 2015;92:627-33.

25. Efstathiou JA, Mouw KW, Gibb EA, et al. Impact of immune and stromal infiltration on outcomes following bladder-sparing trimodality therapy for muscle-invasive bladder cancer. Eur Urol 2019;76:59-68.

26. Simon GR, Schell MJ, Begum M, et al. Preliminary indication of survival benefit from ERCC1 and RRM1tailored chemotherapy in patients with advanced nonsmall cell lung cancer: evidence from an individual patient 
analysis. Cancer 2012;118:2525-31.

27. Schild SE, McGinnis WL, Graham D, et al. Results of a Phase I trial of concurrent chemotherapy and escalating doses of radiation for unresectable non-small-cell lung cancer. Int J Radiat Oncol Biol Phys 2006;65:1106-11.

Cite this article as: Deek MP, Yegya-Raman N, Daroui $\mathrm{P}$, Balasubramanian S, Malhotra J, Moore D, Patel M, Wang SJ, Aisner J, Jabbour SK. Overexpression of excision repair crosscomplementing 1 gene associates with higher risk of therapeutic failure after definitive chemoradiation for unresectable nonsmall cell lung cancer. Ann Palliat Med 2021;10(7):7205-7213. doi: 10.21037/apm-21-182
28. De Ruysscher D, Jin J, Lautenschlaeger T, et al. Bloodbased biomarkers for precision medicine in lung cancer: precision radiation therapy. Transl Lung Cancer Res 2017;6:661-9. 